\title{
Simulation of thermodynamic systems with a thermoelectric converter based on the Peltier element for energy efficient management
}

\author{
Alexander Lukyanov ${ }^{1, *}$, Danila Donskoy ${ }^{1}$, Vitaly Bykador ${ }^{1}$ and Mikhail Chuveyko ${ }^{1}$, and \\ Elena Kasyanenko ${ }^{1}$ \\ ${ }^{1}$ Don State Technical University, Rostov-on-Don, Russia
}

\begin{abstract}
This article deals with the problem of dynamic control of thermodynamic systems based on the Peltier element. The existing methods of relay and PWM control of this object are ineffective and subject the thermoelectric converter to gradual degradation due to transients during switching off and on of the element [1]. The model of a continuous regulator we have created will allow changing the characteristics of the system to determine its behavior for various environmental input parameters. And the use of systems based on continuous control will increase the energy efficiency of the thermoelectric converter and will increase its service life.
\end{abstract}

\section{Introduction}

The thermoelectric converter - Peltier element is currently causing great interest when creating small systems (with a small volume) with automatic control of microclimate parameters. The main difficulties in creating such systems are complex physical principles of the thermoelectric converter itself. Therefore, when creating climate control systems, they are usually limited to stationary states of the element and the task of the control itself is lost, since Peltier works only at a certain power. Thus, the efficiency of the use of the Peltier element is very small, they consume more power, throughout the entire time of work. Our model allows us to determine the behavior of the system with various external factors and, if necessary, select the coefficients of the continuous controller for the dynamic control of the Peltier element. This minimizes energy costs and increases the energy efficiency of using this element in conjunction with continuous management.

\section{Mathematical description of the heat balance of a system consisting of a storage device in a closed space and external heat exchange with the environment}

The amount of heat inside the accumulator (accumulated in the structures inside the closed space):

*Corresponding author: alexlukjanov1998@gmail.com; dand22@bk.ru 


$$
Q_{\text {in }}=m_{v} c_{v} \Theta_{i n}, \quad d Q_{\text {in }}=m_{v} c_{v} \cdot d \Theta_{i n}
$$

Where $m_{v}$ and $c_{v}$ - the mass and heat capacity of the tree, respectively.

Heat flow providing heat exchange with the external environment through the installation walls

$$
q_{1}=S \frac{A}{d}\left(\Theta_{\text {air }}-\Theta_{\text {out }}\right)
$$

Where $S, A$ and $d$ - area, thermal conductivity and thickness of expanded polystyrene (penoplex), respectively.

The mathematical model of the Peltier element can be obtained by the least squares method from the experimentally obtained data of the temperature difference depending on the current strength. This characteristic is presented in Figure 1.

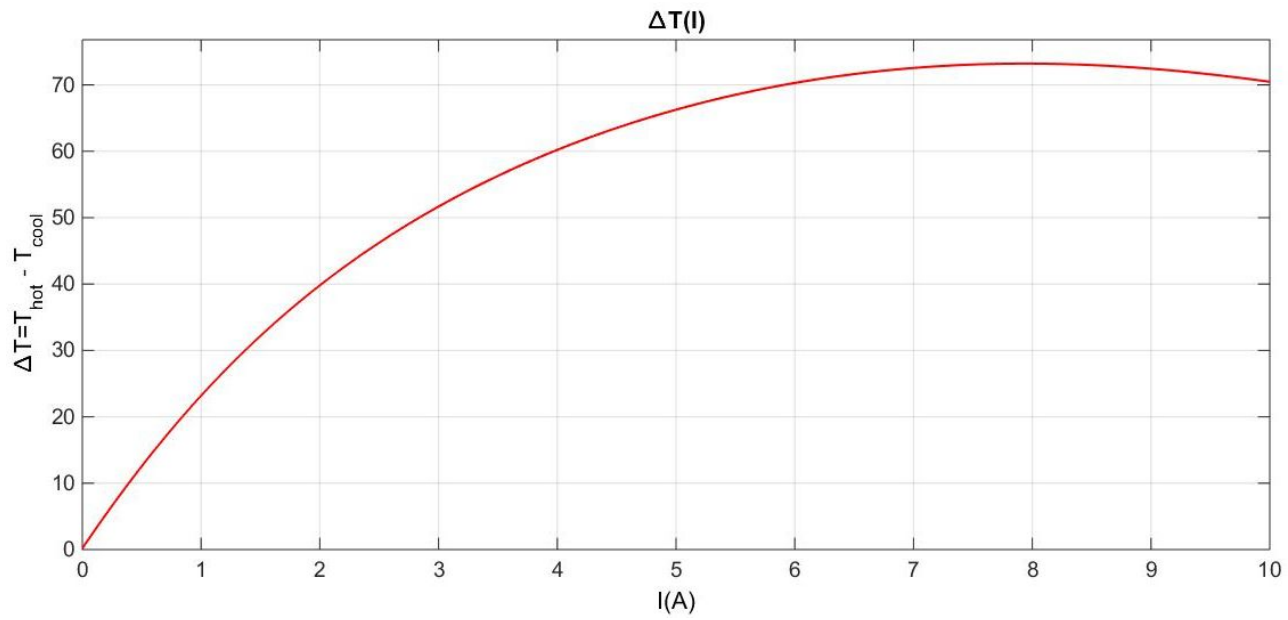

Fig. 1. Graph of the temperature difference from the current strength on the Peltier element.

Consider the heat flow pumped / pumped out by the Peltier element. In this case, we have two streams, one of which is direct, due to the transfer of heat from the hot radiator to the cold one, the other is the reverse, due to the Peltier effect. The characteristic presented in Figure 1 is described quite accurately by a third-order equation:

$$
q_{2}=S_{p} \frac{A_{p}}{d_{p}}\left(\Theta_{\text {hot }}-\Theta_{\text {cool }}\right)-a_{1} i-a_{2} i^{2}-a_{3} i^{3}
$$

Where $S_{p} \frac{A_{p}}{d_{p}} \approx 1-$ Peltier element characteristic, coefficients $a_{1}, a_{2}, a_{3}-$ coefficients obtained by the least squares method from the experimentally obtained characteristics of the Peltier element. $\left(a_{1}=24.67, a_{2}=-2.764, a_{3}=0.1017\right)$

The heat exchange between the external radiator and the external environment is described by the flow:

$$
q_{5}=S_{R h o t}\left(\alpha_{0}+\alpha_{1} v_{R h o t}\right)\left(\Theta_{h o t}-\Theta_{\text {out }}\right)
$$

The heat exchange between the internal radiator and the internal environment is described by the flow: 


$$
q_{4}=S_{\text {Rcool }}\left(\alpha_{0}+\alpha_{1} v_{\text {Rcool }}\right)\left(\Theta_{\text {in }}-\Theta_{\text {cool }}\right)
$$

$\left(\alpha_{0}+\alpha_{1} v_{\text {Rcool }}\right)-$ heat transfer coefficient in moving air.

The amount of heat stored in radiators is described, respectively, by the expressions:

$$
\begin{gathered}
Q_{h o t}=m_{h o t} c_{h o t} \Theta_{h o t}, \quad d Q_{h o t}=m_{h o t} c_{h o t} d \Theta_{h o t} \\
Q_{c o o l}=m_{\text {cool }} c_{\text {cool }} \Theta_{c o o l}, \quad d Q_{\text {cool }}=m_{\text {cool }} c_{\text {cool }} d \Theta_{\text {cool }}
\end{gathered}
$$

The amount of heat stored in the air inside the unit is:

$$
Q_{\text {air }}=V_{\text {air }} \rho_{\text {air }} c_{\text {air }} \Theta_{\text {air }}, \quad d Q_{\text {air }}=V_{\text {air }} \rho_{\text {air }} c_{\text {air }} d \Theta_{\text {air }}
$$

The change in the density and heat capacity of air is neglected. flow:

The heat exchange between the air and the storage structures will be described by the

$$
q_{3}=S\left(\alpha_{0}+\alpha_{1} v_{\text {in }}\right)\left(\Theta_{\text {in }}-\Theta_{\text {air }}\right), \quad v_{\text {in }} \cong v_{\text {Rcool }} / 10
$$

LED power:

$$
q_{6}=P_{L C D} I_{L C D}
$$

\begin{tabular}{|c|c|c|c|c|c|}
\hline \multirow[t]{2}{*}{ № } & \multirow[t]{2}{*}{ Name } & \multicolumn{2}{|c|}{ Designation } & \multirow{2}{*}{$\begin{array}{l}\text { Value } \\
\text { (range) }\end{array}$} & \multirow[t]{2}{*}{ Dimension } \\
\hline & & In the article & In the model & & \\
\hline 1 & \multicolumn{5}{|c|}{ Physical constants } \\
\hline 1.1 & $\begin{array}{l}\text { heat transfer coefficient in } \\
\text { resting air }\end{array}$ & $\alpha_{0}$ & a_0 & 5.6 & $\mathrm{~W} /\left(\mathrm{m}^{2} \mathrm{~K}\right)$ \\
\hline 1.2 & $\begin{array}{l}\text { heat transfer coefficient to } \\
\text { moving air }\end{array}$ & $\alpha_{1}$ & a_1 & 4 & $\mathrm{~W} /\left(\mathrm{m}^{2} \mathrm{~K}\right)$ \\
\hline 1.3 & air heat capacity & $c_{\text {air }}$ & c_air & 1000 & $\mathrm{~J} /(\mathrm{kg} * \mathrm{~K})$ \\
\hline 1.4 & air density & $\rho_{\text {air }}$ & ro_air & 1.28 & $\mathrm{~kg} / \mathrm{m}^{3}$ \\
\hline 1.5 & $\begin{array}{l}\text { thermal conductivity of plates } \\
\text { and Peltier element material }\end{array}$ & $A_{p}$ & A_p & 1.875 & $\mathrm{~W} /(\mathrm{m} * \mathrm{~K})$ \\
\hline 1.6 & $\begin{array}{l}\text { thermal conductivity of } \\
\text { penoplex }\end{array}$ & $A$ & A & 0.032 & $W /(m * \mathrm{~K})$ \\
\hline
\end{tabular}

System Flow Chart (Fig. 2):

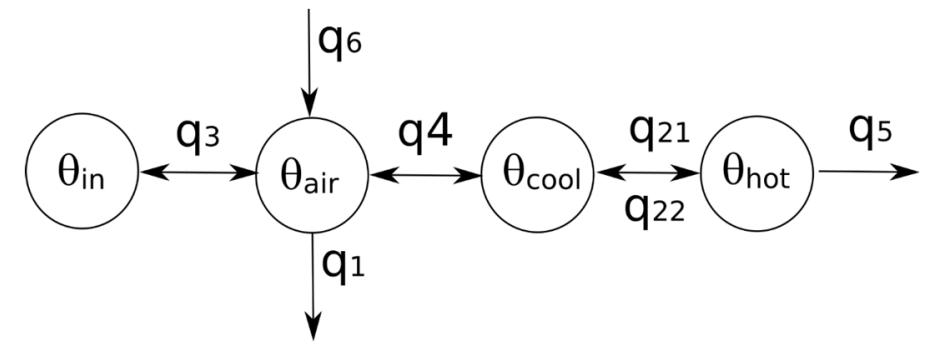

Fig. 2. The structure of the thermodynamic system model.

For convenience, the constants and variables of the model are shown in Table 1.

Table 1. Model parameters [2] 


\section{EEESTS-2019}

\begin{tabular}{|c|c|c|c|c|c|}
\hline 1.7 & aluminum heat capacity & $C_{A L}$ & c_al & 920 & $\mathrm{~J} / \mathrm{K}$ \\
\hline 1.8 & tree heat capacity & $C_{\text {wood }}$ & c_wood & 2300 & $\mathrm{~J} / \mathrm{K}$ \\
\hline 2 & \multicolumn{5}{|c|}{ Technical characteristics of the experimental sample } \\
\hline 2.1 & installation air volume & $V_{\text {air }}$ & V_air & 0.1 & $\mathrm{~m}^{3}$ \\
\hline 2.2 & outer shell area & $S$ & $\mathrm{~S}$ & 1.272 & $\mathrm{~m}^{2}$ \\
\hline 2.3 & wooden structure area & $S_{\text {wood }}$ & S_wood & 0.1 & $\mathrm{~m}^{2}$ \\
\hline 2.4 & $\begin{array}{l}\text { area of internal radiator } \\
\text { cooling }\end{array}$ & $S_{\text {cool }}$ & S_cool & 0.4 & $\mathrm{~m}^{2}$ \\
\hline 2.5 & external radiator cooling area & $S_{\text {hot }}$ & S_hot & 0.4 & $\mathrm{~m}^{2}$ \\
\hline 2.6 & Peltier element area & $S_{p}$ & $\mathrm{~S} \_\mathrm{p}$ & 0.0016 & $\mathrm{~m}^{2}$ \\
\hline 2.7 & Peltier thickness & $d_{p}$ & $d \_p$ & 0.003 & $\mathrm{~m}^{2}$ \\
\hline 2.8 & penoplex thickness & $d$ & $\mathrm{~d}$ & 0.03 & $\mathrm{~m}$ \\
\hline 2.9 & mass of wood & $m_{\text {wood }}$ & m_wood & 0.2 & $\mathrm{~kg}$ \\
\hline 2.10 & $\begin{array}{l}\text { the mass of the internal cooling } \\
\text { radiator }\end{array}$ & $m_{\text {cool }}$ & m_cool & 0.300 & $\mathrm{~kg}$ \\
\hline 2.11 & $\begin{array}{l}\text { mass of external radiator } \\
\text { cooling }\end{array}$ & $m_{\text {hot }}$ & m_hot & 0.300 & $\mathrm{~kg}$ \\
\hline 2.12 & maximum power of LEDs & $P_{L E D}$ & P_led & 50 & $\mathrm{~W}$ \\
\hline 3 & \multicolumn{5}{|c|}{ Impacts } \\
\hline 3.1 & air velocity inside the unit & $V_{\text {in }}$ & $\mathrm{v}$ & 0.01 & $\mathrm{~m} / \mathrm{s}$ \\
\hline 3.2 & internal radiator air flow rate & $V_{\text {cool }}$ & v_cool & 3 & $\mathrm{~m} / \mathrm{s}$ \\
\hline 3.3 & external radiator air flow rate & $V_{\text {hot }}$ & v_hot & 3 & $\mathrm{~m} / \mathrm{s}$ \\
\hline 3.4 & Peltier current & $i_{p}$ & $\mathrm{i} \_\mathrm{p}$ & $\leq 4$ & A \\
\hline 4.5 & $\begin{array}{l}\text { the intensity of the use of } \\
\text { LEDs (from } 0 \text { to } 1 \text { ) }\end{array}$ & $I_{L E D}$ & I_led & $0-0.05$ & - \\
\hline 3.6 & ambient temperature & $\Theta_{\text {out }}$ & Teta_out & 20 & ${ }^{0} \mathrm{C}$ \\
\hline 3.7 & initial temperature conditions & $\Theta_{0}$ & Teta_0 & Teta_out & ${ }^{0} \mathrm{C}$ \\
\hline 4 & \multicolumn{5}{|c|}{ Model state variables } \\
\hline 4.1 & temperature of structures & \multicolumn{4}{|c|}{$\Theta_{\text {wood }}$} \\
\hline 4.2 & air temperature inside & \multicolumn{4}{|c|}{$\Theta_{\text {air }}$} \\
\hline 4.3 & cold radiator temperature & \multicolumn{4}{|c|}{$\Theta_{\text {cool }}$} \\
\hline 4.4 & hot radiator temperature & \multicolumn{4}{|c|}{$\Theta_{\text {hot }}$} \\
\hline 4.5 & Peltier current & \multicolumn{4}{|c|}{$i_{p}$} \\
\hline 4.6 & integral regulator & \multicolumn{4}{|c|}{$X_{P I}$} \\
\hline
\end{tabular}

Let's make the equations of the system, to facilitate their form, simplify the expression of constants:

$$
\begin{gathered}
C M=\frac{1}{m_{\text {wood }} c_{\text {wood }}} \\
S v=S_{\text {wood }}\left(a_{0}+a_{1} v_{\text {in }}\right) \\
S c=S_{\text {cool }}\left(a_{0}+a_{1} v_{\text {cool }}\right)
\end{gathered}
$$




$$
\begin{gathered}
S h=S_{\text {hot }}\left(a_{0}+a_{1} v_{\text {hot }}\right) \\
P q=S \frac{A}{d} \\
P p=S_{p} \frac{A_{p}}{d_{p}} \\
A q=\frac{1}{V_{\text {air }} \rho_{\text {air }} c_{a i r}} \\
M c=\frac{1}{m_{\text {cool }} c_{A l}} \\
M h=\frac{1}{m_{\text {hot }} c_{A l}} \\
\text { Led }=P_{L E D} I_{L E D}
\end{gathered}
$$

In general, the system of equations describing the processes of this system is:

$$
\left\{\begin{array}{c}
\frac{d \theta_{\text {wood }}}{d t}=-C M * S v\left(\theta_{\text {wood }}-\theta_{\text {air }}\right) \\
\frac{d \theta_{\text {air }}}{d t}=\operatorname{Aq}\left(\operatorname{Sv}\left(\theta_{\text {wood }}-\theta_{\text {air }}\right)-P q\left(\theta_{\text {air }}-\theta_{\text {out }}\right)-S c\left(\theta_{\text {air }}-\theta_{\text {cool }}\right)+\text { Led }\right) \\
\frac{d \theta_{\text {cool }}}{d t}=\operatorname{Mc}\left(\operatorname{Sc}\left(\theta_{\text {air }}-\theta_{\text {cool }}\right)-P p\left(\theta_{\text {cool }}-\theta_{\text {hot }}\right)-a_{1} i-a_{2} i^{2}-a_{3} i^{3}\right) \\
\frac{d \theta_{\text {hot }}}{d t}=\operatorname{Mh}\left(\operatorname{Pp}\left(\theta_{\text {cool }}-\theta_{\text {hot }}\right)+a_{1} i+a_{2} i^{2}+a_{3} i^{3}-S h\left(\theta_{\text {hot }}-\theta_{\text {out }}\right)\right) \\
\frac{d i_{p}}{d t}=k_{p}\left(\theta_{\text {air }}-\theta_{Z}\right)+X_{P I} \\
\frac{d X_{P I}}{d t}=k_{i}\left(\theta_{\text {air }}-\theta_{Z}\right)
\end{array}\right.
$$

The last two equations describe the PI controller to control the Peltier element.

\section{The result of mathematical modeling}

The system was studied at an external temperature of 20 degrees with a fluctuation of \pm 5 over a long period of time $\left(10^{5}\right.$ seconds). The Peltier element was required to bring the temperature of the internal environment of the system to $25{ }^{\circ} \mathrm{C}$ set by us. As a result of modeling the system were obtained graphs of energy consumption. Comparative graphs of energy consumption with continuous and relay control can be seen in Figure 3. Savings amounted to $5.6 \%$ 

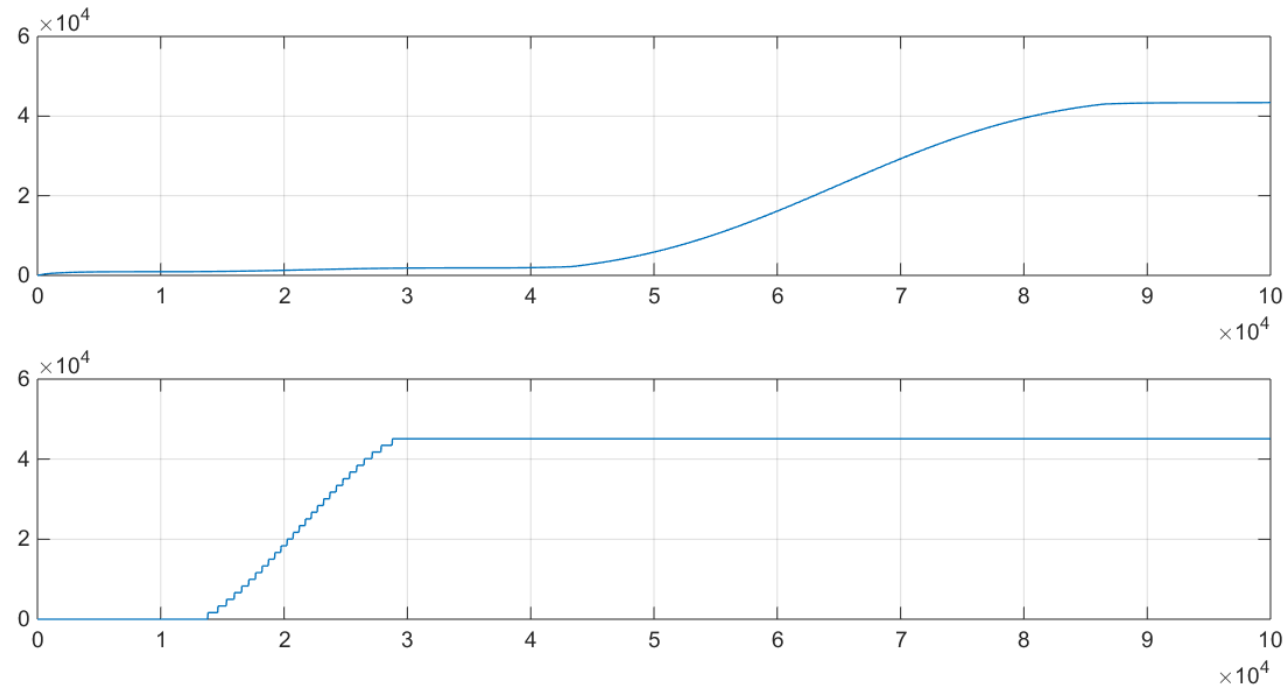

Fig. 3. Energy efficiency of various control methods: 1) continuous method (PI - regulation), 2) Relay method.

\section{Conclusion}

Thus, we have developed a universal model for analyzing the processes occurring when using semiconductor thermoelectric converters. The power consumed in the continuous control of the thermoelectric converter is $5.6 \%$ lower than in the case of relay control, since systems with this element have a large inertia. The model presented by us will allow creating scalable complexes of microclimate maintenance systems that are quite economical and useful both in everyday life and in creating automated greenhouse systems, for example, for preparing and germinating seedlings. The use of continuous control allows you to significantly save on the power consumption of the Peltier element and increase its service life.

\section{References}

1. D.-Y. Pang, W.-S. Jeon, K.-H. Choi, ICCAS2005 (2005)

2. X. Li, Z. Zhong, J. Luo, Z. Wang, W. Yuan, G. Zhang, C. Yang, and C. Yang, International Journal of Photoenergy, 2019, 3725364, DOI: 10.1155/2019/3725364

3. M. D. Thakor, S. K. Hadia, and A. Kumar, 2015 International Conference on Communications and Signal Processing (ICCSP), 1118 (2015), DOI: 10.1109/ICCSP.2015.7322677

4. M. S. Mohamed, M. G. Hassan and A. A. Aly, International Journal of Applied Engineering Research, 13, 1, 1 (2018)

5. Tec1-12706 Datasheet. pdf/view/227422/ETC2/TEC1-12706.html

6. Choosing and Using Advanced Peltier Modules for Thermoelectric Cooling. https://www.digikey.com/en/articles/techzone/2018/feb/choosing-using-advancedpeltier-modules-thermoelectric-cooling 